\title{
S.O.S. VILA MARCONDES
}

Karin Fernanda Schwambach ${ }^{1}$, Mariana Maia Fernandes ${ }^{2}$, Flavia Dias Martins ${ }^{2}$, Lana Mika Ota ${ }^{2}$

${ }^{1}$ Msc. Arquitetura e Urbanismo. ${ }^{2}$ Discente do Curso de Arquitetura e Urbanismo da UNOESTE. E-mail: karin.schwambach@yahoo.com.br

\section{RESUMO}

A Vila Marcondes é um dos poucos locais de Presidente Prudente (SP) que apresenta na rua Quintino Bocaiúva, a composição da paisagem praticamente intacta com edificações que datam da fundação da cidade. Assim sendo, objetivo principal desta pesquisa é de valorizar este fato e contribuir com o resgate da memória da cidade. Constatou-se que a lembrança da Vila Marcondes está adormecida na memória de muitos, e por esse motivo, os alunos agiram por meio de uma intervenção artística temporária nas fachadas desses edifícios e uma passeata em prol do patrimônio histórico e a valorização do bairro como um todo. Além disso, buscou identificar os elementos e apontando diretrizes de ações de melhorias para preservação desta área. $O$ resultado é apresentado em um diagrama que sistematiza as principais ações que deveriam ser levadas em consideração, visando melhorar a qualidade urbana para os moradores do bairro e preservar a arquitetura da cidade.

Palavras-chave: Vila Marcondes; Presidente Prudente; Intervenção Urbana; Patrimônio Histórico; Leitura da Paisagem Urbana.

\section{INTRODUÇÃO E OBJETIVO}

Considerando o valor histórico-social da Vila Marcondes de Presidente Prudente (SP), para as presentes e futuras gerações, admite-se o dever de preservá-lo com políticas e intervenções adequadas.

Um dos principais elementos para fomentar isso, é o despertar de consciência da sociedade, que, conhecendo mais a história de sua cidade espera-se que cumpram seus papéis, valorizando e cobrando medidas de proteção e manutenção do patrimônio arquitetônico.

Assim sendo, realizou-se a leitura da Vila Marcondes com o foco para a valorização do patrimônio arquitetônico que lá existe. Desenvolveu-se uma proposta de intervenção urbana "SOS Vila Marcondes. Movimentando o Patrimônio", colocou a Vila Marcondes nos holofotes, chamando a atenção da mídia, dos citadinos e do poder público de uma forma lúdica, informativa e crítica.

Além disso, sistematizou-se o cenário atual do bairro e elencou-se quatro tópicos que devem ser estudados em projetos futuros visando a melhoria para a população residente mantendo viva a memória da cidade. Em momento algum se almejou esgotar esse assunto, mas contribuir com o estudo urbano da área e aquecer o debate acadêmico. 


\section{METODOLOGIA}

O trabalho foi realizado em várias etapas: levantamentos de dados bibliográficos para compreensão da área de estudo, pesquisa de campo, estudo de percepção do local, intervenção urbana e sistematização dos resultados. Foram realizados estudos e levantamentos socioeconômicos, históricos, de infraestrutura e mapeamentos.

Através da metodologia de Kevin Lynch (2006), foram elaborados mapas mentais, identificando os elementos que compõe o bairro segundo o que está presente na memória das pessoas. Além disso, utilizou-se elementos de leitura da paisagem sugerida por Gordon Cullen (2006) como percurso, perspectiva, tipologia, apropriação dos espaços.

\section{RESULTADOS}

Ao ler a composição da paisagem urbana que se encontra na Vila Marcondes, foi possível chegar a quatro tópicos que clamam por discussões, projetos, idéias e ações : a ligação entre o quadrilátero central e a Vila Marcondes, o tráfego intenso de ônibus e carros, o conjunto de edificações do início do séc. XX, e o rico capital social.

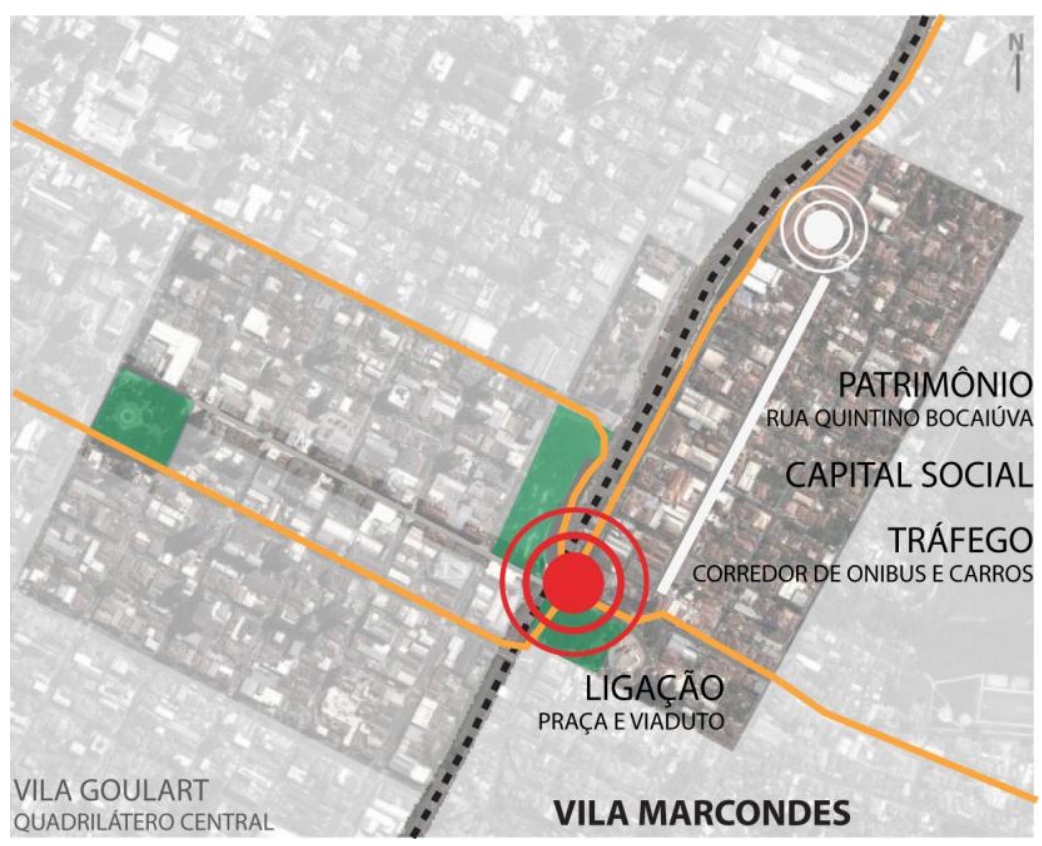

Figura 1. Diagrama com o resultado da leitura da Vila Marcondes

Fonte: Elaborado pelas autoras.

Não são somente esses quatro elementos que necessitam atenção, mas foram os elementos que resolvemos dar destaque, por considerar elementos estruturais e a correta atuação nesses pontos, desencadeará benefícios a Vila Marcondes e a Prudente. 


\section{DISCUSSÃO}

A Vila Marcondes surgiu em 1919, dois anos após a Vila Goulart, do outro lado da linha férrea. Juntas são consideradas o berço da cidade de Presidente Prudente/SP, que apesar das semelhança de idade, passaram por processos urbanos que as diferenciam.

Enquanto o lado da Vila Goulart conduziu o crescimento da cidade, ainda hoje é o principal centro de comércio e serviços. Vila Marcondes estagnou não avançando por um longo período.

Vastas são as razões para tal desenvoltura, tais como: os interesses econômicos, influência política dos proprietários das terras, aspectos físicos como a inserção da estação ferroviária com abertura para a Vila Goulart em 1930, a construção do viaduto em 1970, e o traçado íngreme da topografia dos terrenos.

Justamente em consequência a esse desinteresse imobiliário é que a Vila Marcondes conseguiu preservar a sua arquitetura compondo a paisagem urbana com edificações datadas do início do séc. XX.

Diante da lógica capitalista que atualmente rege tantas transformações nas cidades, principalmente nos centros históricos, são poucos os locais que não passaram esse processo de transformação e conseguem permanecer fiéis a formação original, mantendo as tipologias, escalas, a perspectiva, composição da paisagem.

- Identificação dos elementos

A degradação do bairro se deve a uma série de fatores, como: a construção da estação no lado oposto, ao fim do transporte de passageiro pela ferrovia, construção do Viaduto Comendador Tannel Abud, esquecimento do setor público, crescimento urbano que tomou rumos opostos e a consequente desvalorização imobiliária que intensificou números edificações abandonadas.

Foram identificados quatro elementos que destacaram na pesquisa pela necessidade de intervenção, afim de obter uma melhor articulação, fluidez, conservação da memória da cidade e qualidade de vida na vila.

a) Viaduto Comendador Tannel Abud - o Pontilhão

$\mathrm{O}$ acesso à Vila Marcondes para os veículos automotores é dado pelo viaduto sob ferrovia e para pedestres é dado por um túnel abaixo dos trilhos. Isso gera uma divisão bem acentuada na conexão do bairro com o quadrilátero central. Atualmente em baixo do pontilhão, tem-se um local com baixa qualidade urbana, falta de manutenção na infraestrutura, intenso tráfego de veículos, comércio informal, abrigo para pessoas em situação de rua.

A pesquisa revelou que o apelido da Vila Marcondes é "além-linha", descrito como um local depois da linha férrea com casas velhas, um local de passagem para outros pontos da cidade, 
e um local sem mudanças de uma situação que se estende a anos, cuja esperança de melhoria está longe de acontecer.

A linha férrea forma uma barreira não apenas física como também psicológica para essa área, Jacobs $(2009$, p.286) chama de fronteiras sociais a conhecida expressão "do outro lado da linha do trem" e ressalta: "As zonas desvalorizadas e decadentes que encontramos ao lado das linhas férreas nas cidades parecem afetar tudo o que se encontre dentro delas [...]."

Porém, no entendimento de Cullen (2006), o túnel e o viaduto podem ser elementos que permitem uma visão serial da paisagem, cuja sequência de ponto de vistas que dão vida ao percurso.

Para exemplificar, o livro descreve o caso de Oxford, Ipswich e Westminster, que procura retratar a emoção de percurso que apresenta elementos, Cullen $(2006$, p.20) "temos a sensação de desvendar um mistério, de poder vir a descobrir sempre mais alguma coisa se continuarmos a andar."; e prossegue "de um lado a parte da rua que nos encontramos; para lá do arco, o espaço que iremos desembocar, transitando então para uma nova ambiência."

b) Intenso tráfego viário

A Vila Marcondes não só apresenta a ferrovia como barreira física, mas a maneira como o trânsito está organizado atualmente, é uma verdadeira barreira, principalmente nas horas do rush. O desenvolvimento da zona leste, fez da vila um local de passagem, que gerou verdadeiros corredores de ônibus e carros (vide Figura 1 com o traçado dos corredores em alaranjado).

Com tantos veículos motorizados, houve o aumento da poluição sonora, visual, ambiental, inibição da circulação de pedestres, ciclistas, das atividades e pessoas nas ruas, modificando caráter de bairro em certas áreas.

Jan Gehl, autor de Cidade para Pessoas (2013), é um dos maiores defensores na atualidade do resgate a humanização das cidades. Em entrevista a revista AU Arquitetura e Urbanismo (julho, 2012), cita Nova lorque como exemplo o a ser seguido, :

Nova York, uma cidade de 8 milhões de pessoas, pode ser um grande exemplo de que condições muito melhores podem ser conquistadas quando alguém toma a decisão de se preocupar mais com as pessoas, e menos com carros.

É de suma importância um rearranjo da rede de transporte de Presidente Prudente, dando prioridade as pessoas, pois como Gelh (2012) explica: "O carro espreme a vida urbana para fora do espaço público".

c) Capital social 
Ao adentrar-se no bairro, foi possível conhecer o rico capital social que ali existe. Pessoas que trabalhavam na estação ferroviária e que hoje, com mais idade, ainda moram e passeiam livremente pelo bairro, encontram seus conhecidos numa simples caminhada. Famílias que se estabeleceram cujos filhos brincam nas ruas. Cenário que condizente com o que Jane Jacobs (2009) chama de "vida" da cidade, que acontece graças a diversidade de usos presentes no local.

d) Composição paisagem - Rua Quintino Bocaiúva

A Rua Quintino Bocaiúva da Vila Marcondes (vide Figura 1, traço em branco) apresenta riqueza nas curvas das fachadas originais, nos galpões, armazéns e casas. Há o que aprender com essa linguagem, que a cidade conta sem palavras. Essa viagem silenciosa fomenta a reflexão sobre as evoluções que se sucederam e indo mais adiante, a uma visão crítica da realidade.

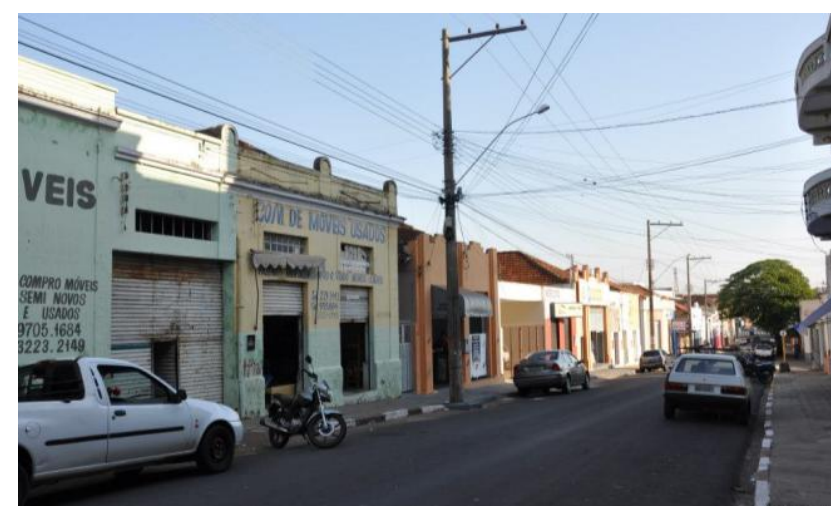

Figura 2. Comércio da rua Quintino Bocaiúva Foto: Karin Schwambach

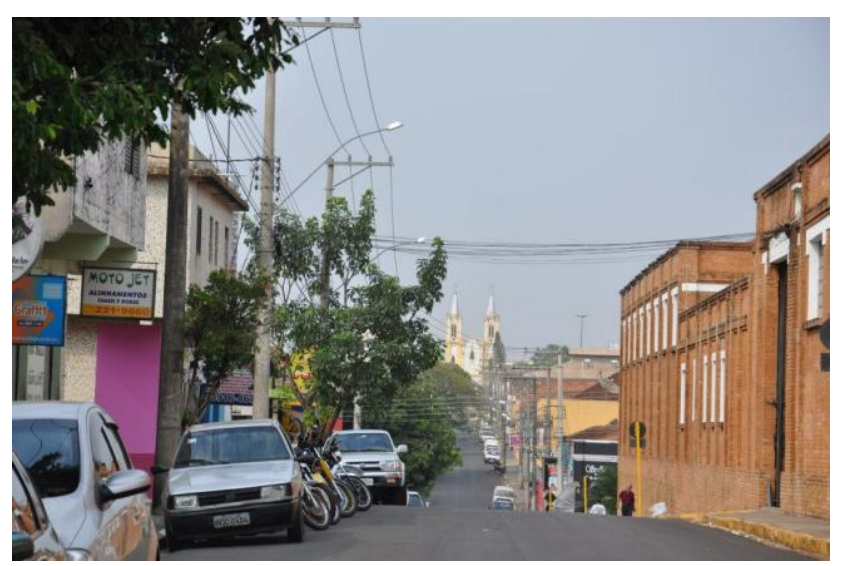

Figura 4. Rua Quintino Bocaiúva, Foto: Karin Schwambach

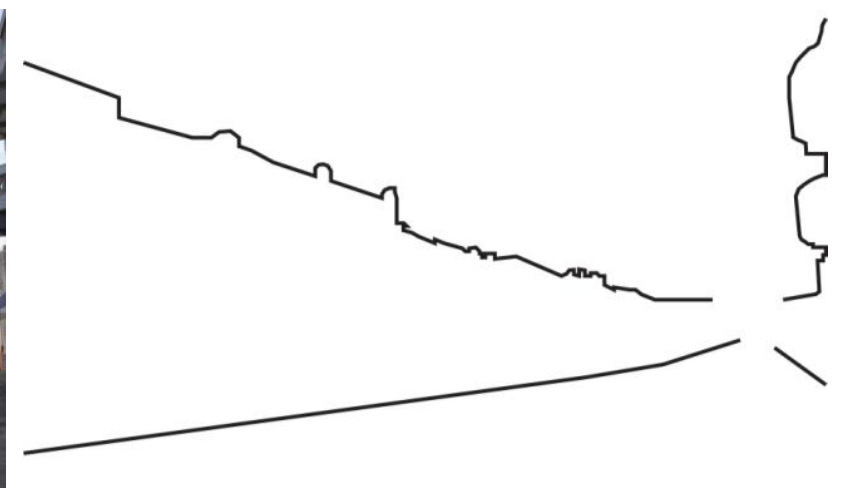

Figura 3. Diagrama de Composição da Paisagem Fonte: Elaborado pelas autoras

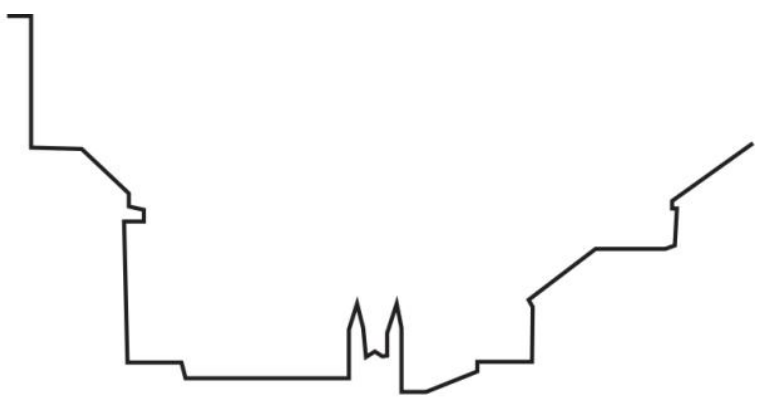

Figura 5. Diagrama de Composição da Paisagem Fonte: Elaborado pelas autoras

As construções antigas fazem parte da memória das pessoas que vivem ou vivenciaram aquele espaço, fazendo com que as mesmas tenham vínculos afetivos aquelas estruturas existentes no local. 
Gordon Cullen (2006) em seu livro Paisagem Urbana, traz diversos exemplos de leitura de diversas paisagens ao redor do mundo, para demonstrar que o entendimento é fundamental para a intervenção no ambiente urbano:

[...] a arte da paisagem construída, a qual se tivesse sido compreendida e levada em prática, teria evitado desastres. Cullen (2006, p.195)

Vale ressaltar que objetivar a preservação da paisagem urbana da Vila Marcondes, não significa "mumificar" este pedaço urbano como nostalgia a um passado que se foi, como melhor explicita Cristina Meneguell (2000):

Na síndrome do patrimônio vivida a partir dos anos 1970-80, e denominada por Pierre Nora como "fúria preservacionista" ou por Choay como "complexo de Noé", a preservação fez-se em nome desse "passadismo". Os edifícios autênticos e seus simulacros, justificados por um vago conceito de democratização cultural, funcionam mais como uma satisfação dada ao intelecto (uma vontade de arte) do que uma experiência artística em si, ou seja, a fruição é dominada pelo afetivo e pelo crivo do nostálgico.

Percebe-se que a riqueza está na diversidade da vila, modificações no desenho urbano, onde os lotes à principio foram divididos seguindo um padrão, foram alterados por seus proprietários de acordo com suas necessidades, gerando casas em terreno compartilhadas, vilas de moradia, ocupação de uso misto como comércio e residência.

Através de uma vista aérea, podemos enxergar um vazio central no lote e com apenas uma edificação de um pavimento no centro, isso acontece porque esses vazios são fundos de lotes não utilizados, ou prolongamento de sua moradia, ou até em outros casos o proprietário ocupa esse espaço para alugar outra casa.

Diagrama com a evolução das divisões dos lotes:

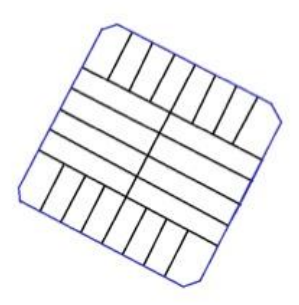

Figura 6. Divisão dos lotes 1920 Fonte: Elaborado pelas autoras

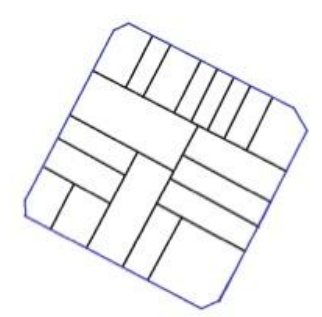

Figura 7. Divisão dos lotes 2012

Fonte: Elaborado pelas autoras

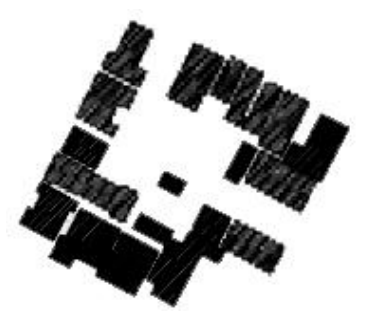

Figura 8. Fundo-figura - 2012 Fonte: Elaborado pelas autoras

Durante a pesquisa, os alunos realizaram uma intervenção artística na Vila Marcondes. Curativos simbólicos foram pregados nas paredes de edificações da Rua Quintino Bocaiúva, que é a rua de maior concentração de comércio e fluxo de pessoas e automóveis, portanto de maior visibilidade. 
Como referência foi utilizado o projeto Curativos Urbanos, que nasceu da inquietude de um grupo de designers e publicitários, que usam bastante a cidade, e discutem a cerca de poluição, mobilidade e espaços públicos, para chamar a atenção tanto da sociedade como do poder público, afim de promover uma visão crítica e melhoria do local.

Adequando a nossa intenção, de promover um novo olhar para o patrimônio histórico presente nas ruas do bairro fundador da cidade, usamos também os curativos, que podem não curar de verdade, mas desejam despertar a atenção de quem pode: "NÓs".

Cartazes com informações históricas foram espalhados por todo o bairro, em pontos específicos como a catedral e a casarões de importância histórica. Realizou-se também uma passeata, utilizando-se de um alto falante e diversos cartazes. A caminhada aconteceu da Praça 9 de julho, por todo o calçadão, até ao Centro Cultural Matarazzo.

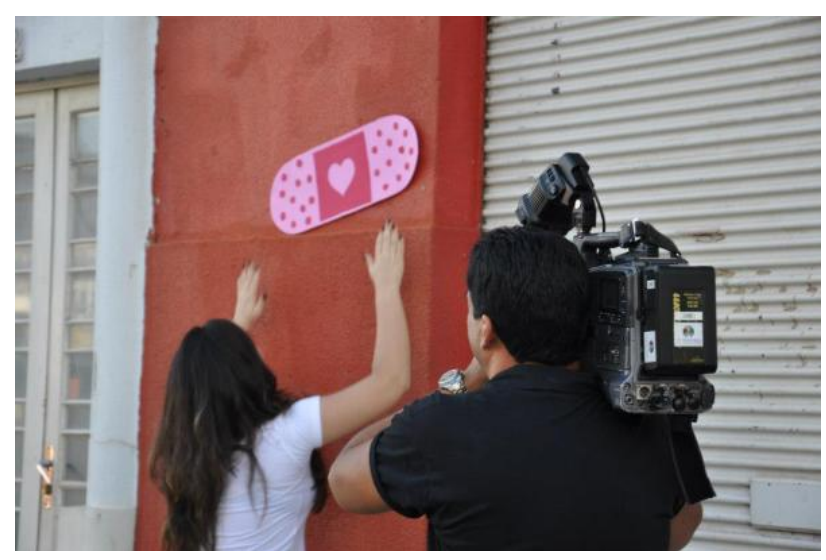

Figura 9. Curativos e a imprensa

Foto: Karin Schwambach

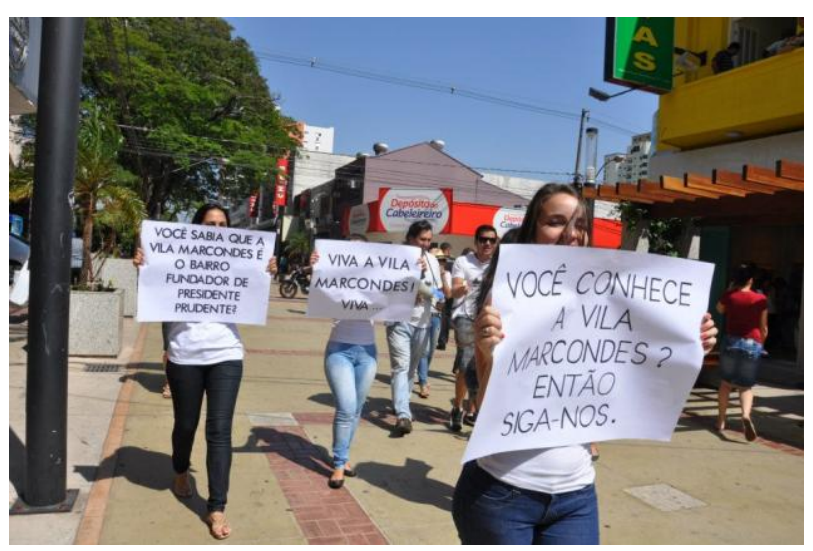

Figura 10. Passeata em prol da Vila Marcondes Foto: Karin Schwambach

A intervenção artística, por ser uma ação única não é possível quantificar os resultados. Sabe-se que presença da mídia disseminou a intervenção para um caráter regional, em todo o oeste paulista, chamando a atenção para a necessidade de elaboração de um programa de valorização do patrimônio histórico-arquitetônico de Presidente Prudente. E é justamente este um dos papéis da intervenção urbana, sobressaltar aos olhos da população para algo que estava obscuro e abandonado.

\section{CONCLUSÃO}

O estudo da Vila Marcondes permitiu ousar e realizar a uma leitura da Vila Marcondes identificando os elementos chaves para área melhoria do bairro. Este bairro que era nos tempos primordiais o principal local de comércio e residências, sofreu as consequências das Colloquium Humanarum, vol. 10, n. Especial, Jul-Dez, 2013, p. 441-448. ISSN: 1809-8207. DOI: 10.5747/ch.2013.v10.nesp.000482 
transformações urbanas regionais como a construção da estação no lado oposto, a inserção do pontilhão, o desuso da linha férrea para passageiros e o crescimento e desenvolvimento oposto da cidade. Isto acarretaram uma frenagem em seu desenvolvimento e um esquecimento de sua representatividade no passado.

A pesquisa e a realização da intervenção urbana, propiciou ao grupo a experiência de reivindicar pela melhoria do bairro e voltar os olhares críticos especificamente para o patrimônio da cidade que está em degradado, justamente por estarem expostas às intempéries e não receberem nenhum tipo de manutenção.

A mudança de consciência é um trabalho lento e progressivo, e esse tipo de ação contribui com a disseminação do conhecimento e do despertar de consciência, necessários para a evolução.

\section{AGRADECIMENTOS}

Este artigo é resultado da pesquisa e do projeto de intervenção urbana "S.O.S. Vila Marcondes. Movimentando o patrimônio histórico.", realizada pelos alunos da disciplina de Urbanismo IV do VI Termo de Arquitetura e Urbanismo da Universidade do Oeste Paulista. Muito obrigada a todos que se empenharam neste trabalho.

\section{REFERÊNCIAS}

BARATTO, Romulo. Curativos Urbanos - um olhar lúdico para os problemas da cidade. Archdaily 28, julho, 2013. Disponível em: < http://www.archdaily.com.br/br/01-130615/curativos-urbanosum-olhar-ludico-para-os-problemas-da-cidade > Acesso em 11 de agosto de 2013.

CULEN, Gordon. Paisagem urbana. Editora 70,1971. 2006.

GEHL, Jan. Gehl fala sobre cidades e escala humana. Revista AU Arquitetura e Urbanismo. São Paulo, artigo 250160-1, jul/2012. Disponível em: <http://www.revistaau.com.br/arquiteturaurbanismo/215/artigo250160-1.asp>. Acesso em 11 de agosto de 2013.

JACOBS, Jane. Morte e vida das grande cidades. São Paulo: Martins Fontes, 1961. 2007.

LYNCH, Kevin. A imagem da cidade. São Paulo: Martins Fontes, 2006.

MENEGUELO, Cristina. A preservação do patrimônio e o tecido urbano. Arquitextos 003.05 ano 01, agosto 2000. Disponível em:

<http://www.vitruvius.com.br/revistas/read/arquitextos/01.003/992 > Acesso em 10 de agosto de 2013.

WHITAKER, Arthur Magon. A produção do espaço urbano em Presidente Prudente: uma discussão sobre a centralidade urbana. Dissertação de Mestrado. Presidente Prudente, Universidade Estadual Paulista "Júlio Mesquita Filho", 1997. 